\title{
Influence of selected factors on bovine spermatozoa cold shock resistance
}

\author{
Luděk Stádník ${ }^{1}$, Radko Rajmon ${ }^{2}$, Jan Beran ${ }^{1}$, Ondřej Šimoník ${ }^{2}$, Martina Doležalová ${ }^{1}$, \\ Jiří Šichtař ${ }^{2}$, Roman Stupka ${ }^{1}$, Petra Folkováa \\ ${ }^{1}$ Czech University of Life Sciences Prague, Faculty of Agrobiology, Department of Animal Husbandry, \\ ${ }^{2}$ Department of Veterinary Sciences, Prague, Czech Republic \\ Received October 22, 2014 \\ Accepted February 25, 2015
}

\begin{abstract}
The objectives of this study were to determine the effects of sire, extender, and addition of Low Density Lipoprotein (LDL) to extenders used on the percentage rate of spermatozoa survival after cold shock. Two groups of extenders were compared: without LDL addition (control variants) and LDL enriched (experimental variants). Three extenders were used: AndroMed ${ }^{\circledR}$, Bioxcell ${ }^{\mathbb{}}$, and Triladyl ${ }^{\circledR}$. Experimental variants included $4-8 \%$ LDL addition into the AndroMed ${ }^{\circledR}$ and Bioxcell $^{\circledR}$ extenders, and 6-10\% LDL addition into the Triladyl ${ }^{\circledR}$ extender. In total, 12 samples of fresh semen were collected from 4 bulls during a period of 8 weeks. Bovine spermatozoa cold shock resistance $\left(1 \pm 1{ }^{\circ} \mathrm{C}, 10 \mathrm{~min}\right)$ was evaluated by the percentage rate of live sperm using eosin-nigrosine staining immediately and after heat incubation $\left(37 \pm 1{ }^{\circ} \mathrm{C}, 120 \mathrm{~min}\right)$. The results showed the effect of sire as important and individual differences between selected sires in their sperm resistance against cold shock were confirmed. AndroMed ${ }^{\circledR}$ and Bioxcell ${ }^{\circledR}$ were found to be providing better protection of bull semen to cold shock compared to Triladyl ${ }^{\circledR}$ due to lower decline of live sperm proportion. Our results detected a positive effect of LDL addition on sperm resistance against cold shock, especially on lower decrease of live sperm percentage rate after $120 \mathrm{~min}$ of the heat test $(P<0.05)$. Further studies are needed to assess the optimal concentration of LDL in various kinds of extenders as well to state ideal time and temperature conditions for ensuring LDL reaction with sperm.
\end{abstract}

Reproduction, bull sperm, extender, LDL cholesterol, sperm survival, cold shock, eosin-nigrosine staining

Fertility of dairy cows has declined over the past five decades as milk production per cow has increased (Walsh et al. 2011). Cattle fertility has been intensively studied in recent years with regard to females (Hanuš et al. 2010; Beran et al. 2013a). However, cows' reproduction results are affected by the male component as well.

Sperm quality is influenced by many internal and external factors, e.g. breed, variation between individuals, age of sire (Thara and Nair 2007; Beran et al. 2012; Härtlová et al. 2013), environmental conditions (Balić et al. 2012), and frequency of collecting the ejaculate (Karoui et al. 2011). Collection of the ejaculate and its subsequent processing present further potential risk factors for declined sperm quality. The steps of producing insemination doses (diluting the sperm, filling the straws, cooling and freezing) have a significant effect on sperm motility after thawing (Siddique et al. 2006). Especially, the properties of extender used (Crespilho et al. 2012; Cao et al. 2013; Špaleková et al. 2014) and freezing methods are important (Watson 2000; Medeiros et al. 2002).

In general practice, different types of semen extenders are used. They can be divided according to the type of cryoprotective substance into skimmed-milk extenders, extenders based on plant phospholipids, and extenders containing egg yolk (Vishwanath and Shannon 2000). Pace and Graham (1974) found that the important component of egg yolk responsible for its cryoprotective properties is low density lipoprotein (LDL) and they concluded that LDL can protect bull sperm as efficiently as fresh egg yolk. Furthermore,

Address for correspondence:

Assoc. Prof. Ing. Luděk Stádník, Ph.D.

Department of Animal Husbandry

Faculty of Agrobiology, Food and Natural Resources

Czech University of Life Sciences Prague

Kamýcká 129, 16521 Prague 6 - Suchdol, Czech Republic 
replacement of egg yolk only by its active LDL fraction can prevent microbial risks, as the results of the study Bousseau et al. (1998) showed that commercially produced egg yolk extenders could be bacterial contaminated. The mechanism of the LDL protective action has not yet been completely explained. However, the positive effects of LDL were reported by Bergeron and Manjunath (2006). They identified that the family of phospholipid-binding proteins (BSP proteins) present in seminal plasma are detrimental to sperm preservation since they interact with LDL. This interaction prevents lipid efflux from sperm and positively influences sperm storage in liquid or frozen states, but the optimal time and temperature conditions of the abovementioned interaction have not been sufficiently explored yet. It is assumed that extenders containing LDL, which is extracted from egg yolk, might have more positive effects on spermatozoa membranes during the freezing than commercially used diluters (Moussa et al. 2002).

Biological tests of the ejaculate have been developed to assess the resistance and fertilization ability of sperm using LDL addition into diluters, e.g. short-term heat test of sperm survival (Maurya and Tuli 2003) or hypo-osmotic swelling tests (Přinosilová et al. 2014). However, resistance of sperm against cold shock has not been evaluated as well in relation to the addition of LDL. Moreover, the results of a previous study (Beran et al. 2013b) have shown different results in relation to the concentration of LDL.

Thus, the aim of this study was to determine the effects of sire, extender, and addition of LDL to extenders used on the percentage rate of spermatozoa survival after cold shock.

\section{LDL extraction \\ Materials and Methods}

Low density lipoprotein (LDL) was prepared in accordance with the methodology of Moussa et al. (2002). Hen eggs were obtained from Biopharm Inc. (Pohoří - Chotouň, Czech Republic), and production of the LDL fraction was ensured by the company Hena Inc. (Prague, Czech Republic). Firstly, egg yolk had to be separated from albumen manually, by rolling on filter paper in order to remove the endosperm and chalaza. Then the vitellin membrane was cut with a scalpel, and egg yolks were collected in a tube kept refrigerated by ice at $4{ }^{\circ} \mathrm{C}$. In this way egg yolk plasma obtained was diluted by $0.17 \mathrm{M} \mathrm{NaCl}$ solution and then stirred for 60 min. Afterwards, centrifugation at $10,000 \times g$ for $45 \mathrm{~min}$ at $10^{\circ} \mathrm{C}$ was performed and after supernatant removal, the procedure was repeated. The main purpose of this centrifugation was to achieve the separation of egg yolk granules from plasma. The obtained egg yolk plasma was stored at $4{ }^{\circ} \mathrm{C}$. Then, $20.5 \mathrm{~g}$ of ammonium sulphate was added to $100 \mathrm{ml}$ of plasma for removal of livetines, and this was stirred for $1 \mathrm{~h}$ at $\mathrm{pH} 8.7$ and temperature $4{ }^{\circ} \mathrm{C}$. Precipitated livetines were subsequently separated by centrifugation at $10,000 \times \mathrm{g}$ for $45 \mathrm{~min}$. The supernatant was then dialyzed further $10 \mathrm{~h}$ for the purpose of ammonium sulphate elimination and selective coagulation of LDL. At the end of this dialysis the mixture was centrifuged at $10,000 \times g$ for $45 \mathrm{~min}$, and the resulting sediment (pellets) represented LDL with a purity of $97 \%$, which had to be stored at $4{ }^{\circ} \mathrm{C}$.

\section{Extender preparation}

Two groups of extenders were compared in this experiment: without LDL addition (control variants) and LDL enriched (experimental variants). Three commercially available extenders were used: AndroMed ${ }^{\circledR}$ extender containing plant phospholipids (MiniTüb GmbH, Tiefenbach, Germany), Bioxcell ${ }^{\circledR}$ non-egg yolk extender (IMV, L' Aigle, France), and Triladyl ${ }^{\circledR}$ containing $20 \%$ of egg yolk (MiniTüb GmbH, Tiefenbach, Germany). Experimental variants included 4-8\% LDL addition to the AndroMed ${ }^{\circledR}$ and Bioxcell ${ }^{\circledR}$ extenders, and 6-10\% LDL addition into the the Triladyl ${ }^{\circledR}$ extender. The higher proportion of LDL addition in Triladyl ${ }^{\circledR}$ replaced the egg yolk which is normally its essential component. All the extenders were prepared on the day of sampling from one batch number according to the instructions of the producers and stored in a cooling box $\left(5-10{ }^{\circ} \mathrm{C}\right)$ before ejaculate dilution.

\section{Semen collecting, dilution and processing}

Semen was collected from 4 bulls of same age, breed and frequency of collecting, bred in one sire insemination center (Natural Ltd., Hradištko pod Medníkem, Czech Republic) approved for public use in a standard way. Because climatic conditions during the observation period were similar, we did not include the effect of climatic conditions in the statistical model.

In total of 12 sampling days, ejaculate samples were obtained using an artificial vagina. Volume of fresh semen (VOL), density of sperm (DEN), and percentage rate of progressive motile spermatozoa above head (ACT) were evaluated by only one trained technician of the sire insemination centre. The mean volume of collected semen was $9.78 \mathrm{~g}$. The mean sperm density was $1.28 \times 10^{6} \mathrm{~mm}^{-3}$. Proportion of progressive motile spermatozoa above 
head detected immediately after collection was $87.50 \%$. The mean percentage rate of live sperm was $74.12 \%$ in the beginning and $54.37 \%$ after 120 min of heat incubation.

Samples of fresh semen were divided into 12 portions $\left(1\right.$ control - Andromed ${ }^{\circledR}$, Bioxcell $^{\circledR}$ as well as Triladyl $l^{\circledR}$; 3 experimental variants per extender - Andromed ${ }^{\circledR}$ and Bioxcell ${ }^{\circledR}$ with $4 \%, 6 \%$, and $8 \%$ LDL as well as Triladyl ${ }^{\circledR}$ with $6 \%, 8 \%$, and $10 \% \mathrm{LDL})$, and pipetted using a sterile pipette to a sterile chilled $\left(5-10{ }^{\circ} \mathrm{C}\right)$ tubes. Each portion was immediately diluted to a concentration of approximately $30 \times 10^{6} / \mathrm{ml}$. The required amount of extenders was applied using sterile pipettes directly to the tubes with samples.

Evaluation of resistance against cold shock

Tube contents were then divided into two portions. The first portion was used for cold shock test: three glass capillaries $(0.1 \mathrm{ml})$ closed at one end with plasticine were successively filled from each tube with diluted sample of semen at $7 \pm 1^{\circ} \mathrm{C}$, and subsequently stored in a cool bath (No Ice, Bibby Scientific, Ltd., Staffordshire, UK) for $10 \mathrm{~min}\left(1 \pm 1^{\circ} \mathrm{C}\right)$. After the end of cold incubation the content of capillaries was gently mixed on preheated hour glass $\left(37 \pm 1^{\circ} \mathrm{C}\right)$ with $20 \mu \mathrm{l}$ of eosin by circular motion for $30 \mathrm{~s}$ and then nigrosine was added at the amount of $40 \mu \mathrm{l}$. A volume of $20 \mu \mathrm{l}$ of the resulting suspension was added onto a preheated glass slide and smear was done.

The second portion of diluted semen was stored in a water bath at $37 \pm 1{ }^{\circ} \mathrm{C}$ for $120 \mathrm{~min}$. After that time the cold shock test was repeated by the above mentioned methodology. A total of 576 smears were thus collected (12 collecting days, 4 bulls, 3 extenders used, and 4 samples per extender).

Dried smears were examined under a phase contrast microscope (Eclipse E200, Nikon ${ }^{\circledR}$, Tokyo, Japan) at $\times 1000$ magnification and with oil immersion by only one evaluator. A minimum of 100 spermatozoa were classified as either dead (with red heads) or live (with white heads) and expressed as the percentage rate of live sperm at the beginning of the test (LS0) and after $120 \mathrm{~min}$ of heat incubation (LS120).

Statistical analysis

The data were evaluated with the statistical software SAS ${ }^{\circledR}$ (Version 9.3; SAS Inst., Inc., Cary, NC, USA) using MIXED procedure. The following equation was used:

$\mathrm{Y}_{\mathrm{ijkl}}=\mu+\mathrm{SIRE}_{\mathrm{i}}+\mathrm{EXT}_{\mathrm{j}}+\mathrm{LDL}_{\mathrm{k}}+\mathrm{b}_{1} *(\mathrm{VOL})+\mathrm{b}_{2}^{*}(\mathrm{DEN})+\mathrm{b}_{3}^{*}(\mathrm{ACT})+\mathrm{e}_{\mathrm{ijkl}}$, where:

$\mathrm{Y}_{\mathrm{ijkl}}=$ observed value of the dependent variable (percentage rate of live sperm at the beginning of the test and after 120 min heat incubation, difference between these two measurements),

$\operatorname{SIRE}_{\mathrm{i}}=$ fixed effect of the $\mathrm{i}^{\text {th }}$ sire $(\mathrm{i}=1, \mathrm{n}=144 ; 2, \mathrm{n}=144 ; 3, \mathrm{n}=144 ; 4, \mathrm{n}=144)$;

EXT $_{i}=$ fixed effect of the $j^{\text {th }}$ extender $\left(j=1-\right.$ AndroMed $^{\circledR}, n=192 ; 2-$ Bioxcell $^{\circledR}, n=192 ; 3-$ Triladyl $^{\circledR}$, $\mathrm{n}=192)$;

$\mathrm{LDL}_{\mathrm{k}}=$ fixed effect of the $\mathrm{k}^{\text {th }}$ presence of LDL $(\mathrm{k}=\mathrm{NO}, \mathrm{n}=144$; YES, $\mathrm{n}=432)$;

$b_{1} *(\mathrm{VOL})=$ regression on initial volume of fresh ejaculate;

$\mathrm{b}_{2} *(\mathrm{DEN})=$ regression on initial density of sperm in fresh ejaculate;

$\mathrm{b}_{3}{ }^{*}(\mathrm{ACT})=$ regression on initial activity of sperm in fresh ejaculate;

$\mathrm{e}_{\text {iikl }}=$ residual effects.

The differences between the variables estimated were tested at the levels of significance $P<0.05, P<0.01$, and $P<0.001$.

\section{Results}

Model repeatability ranged from $\mathrm{r}^{2}=0.406$ to $\mathrm{r}^{2}=0.852$ during the evaluation of observed traits when the significance of the whole model was $P<0.001$ in all evaluations as well as the effect of volume, density and activity regression. The effect of sire was significant $(P<0.01)$ in relation to all the evaluated traits. The effect of extender was significant $(P<0.001)$ in relation to the percentage rate of live sperm after $120 \mathrm{~min}$ of heat incubation and difference between the percentage rate of live sperm at the beginning and $120 \mathrm{~min}$ of the test. The effect of LDL presence in the tested samples was significant $(P<0.05)$ to the percentage rate of live sperm at the beginning of the test and the difference between the percentage rate of live sperm at the beginning and after $120 \mathrm{~min}$ of the test.

The results from MIXED procedure for the fixed effect of sire are given in Table 1. Significant differences $(P<0.05)$ in sperm survivability after cold shock were detected between sires regardless of the extender used or presence of LDL. The highest percentage rate of live sperm at the beginning of the test (LS0) was achieved by sire no. $2(78.39 \pm$ $1.086 \%$ ), while the highest survivability after $120 \mathrm{~min}$ of the test (LS120) was achieved by sire no. $1(64.19 \pm 1.799 \%)$, including the lowest difference between LS0 and LS120 $(11.01 \pm 1.742 \%)$. Significantly $(P<0.01)$ the lowest values of sperm survivability 
Table 1. Effect of sire on sperm survivability after cold shock.

\begin{tabular}{lccc}
\hline Sire & LS0 & LS120 & LS0 - LS120 \\
\hline 1 & $74.96 \pm 1.195^{\mathrm{A}}$ & $64.19 \pm 1.799^{\mathrm{A}}$ & $11.01 \pm 1.742^{\mathrm{A}}$ \\
2 & $78.39 \pm 1.086^{\mathrm{A}}$ & $56.13 \pm 1.619^{\mathrm{B}}$ & $22.32 \pm 1.568^{\mathrm{a}, \mathrm{B}}$ \\
3 & $75.27 \pm 1.624^{\mathrm{A}}$ & $61.99 \pm 2.407^{\mathrm{A}, \mathrm{B}}$ & $13.05 \pm 2.331^{\mathrm{b}, \mathrm{A}, \mathrm{B}}$ \\
4 & $54.23 \pm 3.437^{\mathrm{B}}$ & $14.76 \pm 5.149^{\mathrm{C}}$ & $38.86 \pm 4.986^{\mathrm{b}, \mathrm{B}, \mathrm{C}}$ \\
\hline
\end{tabular}

LS $0=$ percentage of live sperm at the beginning of the test; LS120 = percentage of live sperm after 120 min of the test; LS0 - LS120 = difference between percentage of live sperm at time 0 and $120 \mathrm{~min}$ of the test; different superscripts mean a significant difference within a column $-\mathrm{a}, \mathrm{b}=P<0.05 ; \mathrm{A}, \mathrm{B}, \mathrm{C}=P<0.01$

Table 2. Effect of extender on sperm survivability after cold shock.

\begin{tabular}{lccc}
\hline Extender & LS0 & LS120 & LS0 - LS120 \\
\hline AndroMed $^{\circledR}$ & $71.22 \pm 1.027$ & $54.44 \pm 1.515^{\mathrm{A}}$ & $16.78 \pm 1.468^{\mathrm{A}}$ \\
Bioxcell $^{\circledR}$ & $71.46 \pm 1.027$ & $50.17 \pm 1.516^{\mathrm{B}}$ & $21.07 \pm 1.469^{\mathrm{B}}$ \\
Triladyl $^{\circledR}$ & $69.46 \pm 1.027$ & $43.19 \pm 1.529^{\mathrm{C}}$ & $26.09 \pm 1.481^{\mathrm{C}}$ \\
\hline
\end{tabular}

LS $0=$ percentage of live sperm at the beginning of the test; LS120 = percentage of live sperm after 120 min of the test; LS0 - LS120 = difference between percentage of live sperm at time 0 and $120 \mathrm{~min}$ of the test; different superscripts mean a significant difference within a column $-\mathrm{A}, \mathrm{B}, \mathrm{C}=P<0.01$

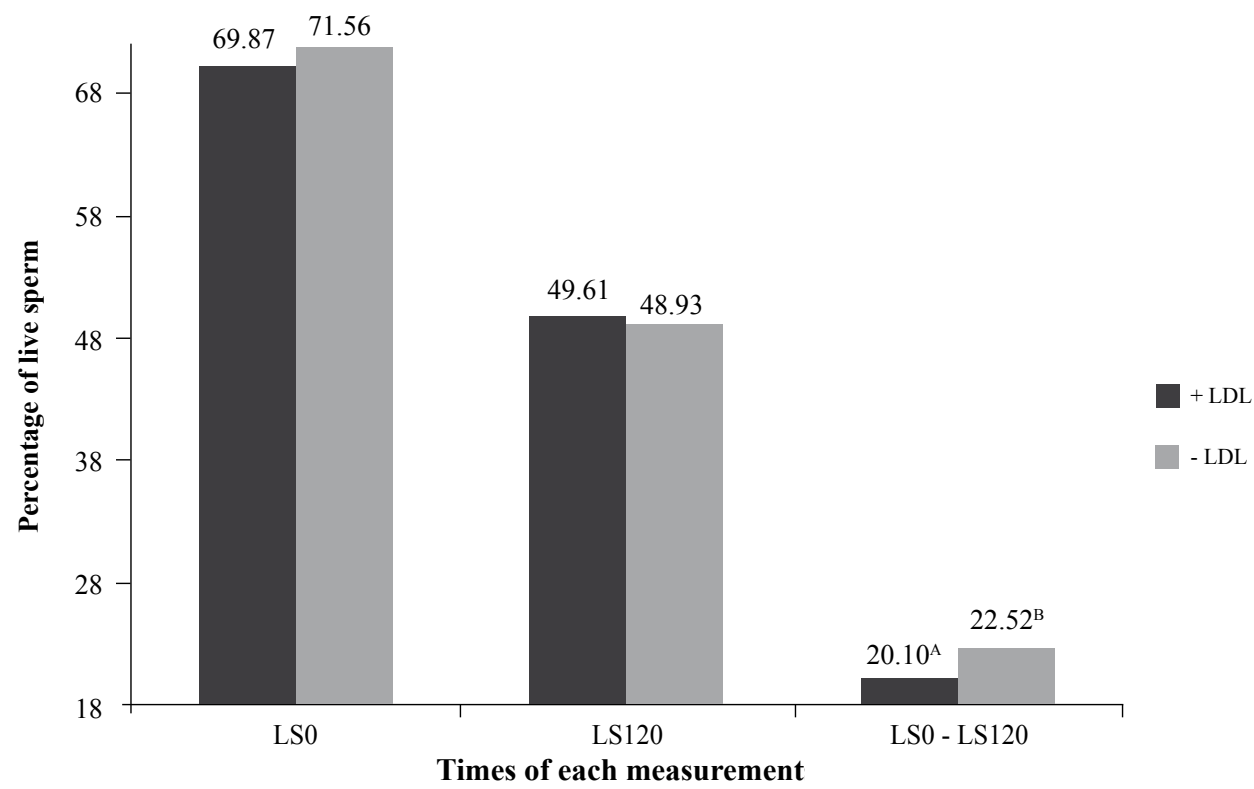

Fig. 1. Effect of LDL addition on sperm survivability after cold shock

LS $0=$ percentage of live sperm at the beginning of the test; LS120 = percentage of live sperm after 120 min of the test; LS0 - LS120 = difference between percentage of live sperm at time 0 and $120 \mathrm{~min}$ of the test; different superscripts mean a significant difference between columns $-\mathrm{A}, \mathrm{B}=P<0.05$ 
during whole test was achieved by sire no. $4(\mathrm{~L} 0=54.23 \pm 3.437$, respectively LS120 $=14.76 \pm 5.149 \%)$. This sire had also significantly $(P<0.05-0.01)$ the highest sperm survivability decline during the test $(38.86 \pm 4.986 \%)$.

Focusing on the influence of the extender used regardless of the presence of LDL and sire effect (Table 2), we can assume that AndroMed ${ }^{\circledR}$ and Bioxcell ${ }^{\circledR}$ showed non-significantly $(P>0.05)$ the highest percentage rate of live sperm at the beginning of the test (LS0 $=71.22 \pm 1.027 \%$, resp. $71.46 \pm 1.027 \%$ ). On the other hand, significantly the lowest percentage rates of live sperm were found in Triladyl ${ }^{\circledR}$ at the beginning (LS0 $=69.46 \pm$ $1.027 \% ; P>0.05)$ and after 120 min of the test compared to Bioxcell ${ }^{\circledR}(-6.98 \% ; P<0.01)$ and AndroMed ${ }^{\circledR}(-11.25 \% ; P<0.01)$. Triladyl ${ }^{\circledR}$ also achieved significantly $(P<0.01)$ the highest decline of the percentage rate of live sperm during the entire test $(26.09 \pm 1.481 \%)$ differing by $5-16 \%$ from the other diluents.

Results of LDL addition influence on sperm survivability without specification of the extender type are also presented in Fig. 1. Significantly $(P<0.05)$ higher percentage rate of live sperm at the beginning of the test had samples without LDL $(\operatorname{LS} 0=+1.69 \%)$ compared to samples containing LDL. On the other hand, opposite results were detected after 120 min of the test, when higher percentage rate of live sperm (LS120 $=+0.68 \% ; P>$ $0.05)$ was achieved by the samples containing LDL. These samples also had significantly $(P<0.05)$ lower difference between time 0 and $120 \mathrm{~min}$ of the test $(20.10 \%)$. These findings indicate that a protective effect of LDL occurred after $120 \mathrm{~min}$ incubation in water bath $\left(37 \pm 1^{\circ} \mathrm{C}\right)$ only.

\section{Discussion}

Our results presented in Table 1 confirmed sires' individuality as an important effect; many significant individual differences were detected between sires. Our findings are in accordance with Thara and Nair (2007), who found that semen from different sires had different fertilization ability in vitro.

Cold shock test belongs to the main evaluation methods of sperm quality (Benson et al. 1967). We focused on evaluation of ejaculate viability and fertility using this test as well. Our results showed that better results of the cold shock test were achieved using AndroMed $^{\circledR}$ and Bioxcell ${ }^{\circledR}$. This is in accordance with Stradaioli et al. (2007) who state AndroMed ${ }^{\circledR}$ and Bioxcell ${ }^{\circledR}$ as the most suitable extenders for cryopreservation of bull semen. However, the general course of reproduction results in cows points out the necessity of continuous improving of extenders. For this reason, the addition of selected cryoprotectant was evaluated and tested.

The positive effect of LDL found in our study has been shown also in several other studies, e.g. by $\mathrm{Hu}$ et al. (2010), and Vera-Munoz et al. (2011). The authors concluded that LDL binds to the cell membrane protecting it from a 'cold shock'. This reaction requires time, and therefore the protective effect of LDL was shown after $120 \mathrm{~min}$, and not immediately after dilution. This finding brings the need to test this reaction in shorter intervals or, on the other hand, during a longer equilibration time, however, under lower temperature. Another advantage of the LDL extender compared to standard egg yolk extender lies in clearly defined and stable chemical composition (Amirat et al. 2004). Manjunath et al. (2002) and Bergeron et al. (2004) stated that LDL has the ability to form very stable complexes with major BSP proteins. This interaction increases the sperm robustness against cold shock. Our results confirmed the mentioned statement.

Based on our monitoring we can assume that the effect of sire is important and individual differences between selected sires in their sperm resistance against cold shock were confirmed. AndroMed ${ }^{\circledR}$ and Bioxcell ${ }^{\circledR}$ have been found to be more suitable extenders for cryopreservation of bull semen compared to Triladyl ${ }^{\circledR}$ due to the lower decline of live 
sperm proportion during the cold shock test. Our results found a positive effect of LDL addition on sperm resistance against cold shock, especially a lower decline of the live sperm percentage rate during $120 \mathrm{~min}$ of the test $(P<0.05)$. Further studies evaluating the LDL effect during and/or after equilibration period are needed. More research is also needed to assess the optimal concentration of LDL in various kinds of extenders and to determine the ideal time and temperature conditions for ensuring LDL reaction with sperm.

\section{Acknowledgments}

The work was funded by "S" grant of MŠMT ČR and project NAZV QJ1210109. We thank the company Natural Ltd. for cooperation on this work and Mrs. Lois Russell for her editorial help with this manuscript.

\section{References}

Amirat L, Tainturier D, Jeanneau L, Thorin C, Gerard O, Courtens JL, Anton M 2004: Bull semen in vitro fertility after cryopreservation using egg yolk LDL: a comparison with Optidyl (R), a commercial egg yolk extender. Theriogenology 61: 895-907

Balić IM, Milinković-Tur S, Samardžija M, Vince S 2012: Effect of age and environmental factors on semen quality, glutathione peroxidase activity and oxidative parameters in simmental bulls. Theriogenology $\mathbf{7 8}$ : 423-431

Benson RW, Pickett BW, Komarek RJ, Lucas JJ 1967: Effect of incubation and cold shock on motility of boar spermatozoa and their relationship to lipid content. J Anim Sci 26: 1078-1081

Beran J, Stádník L, Bezdíček J, Louda F, Cítek J, Ducháček J 2012: Effect of sire and extender on sperm motility and share of live or dead sperm in bulls' fresh ejaculate and in Al doses after thawing. Arch Tierz-Arch Anim Breed 55: 207-218

Beran J, Stádník L, Ducháček J, Okrouhlá M, Doležalová M, Kadlecová V, Ptáček M 2013a: Relationships among the cervical mucus urea and acetone, accuracy of insemination timing, and sperm survival in Holstein cows. Anim Reprod Sci 142: 28-34

Beran J, Šimoník O, Stádník L, Rajmon R, Ducháček J, Krejcárková A, Doležalová M, Šichtař J 2013b: Effect of bull, diluter and LDL-cholesterol concentration on spermatozoa resistance against cold shock. Acta Univ Agric Silvic Mendel Brun 61: 1575-1581

Bergeron A, Crete MH, Brindle Y, Manjunath P 2004: Low-density lipoprotein fraction from hen's egg yolk decreases the binding of the major proteins of bovine seminal plasma to sperm and prevents lipid efflux from the sperm membrane. Biol Reprod 70: 708-717

Bergeron A, Manjunath P 2006: New insights towards understanding the mechanisms of sperm protection by egg yolk and milk. Mol Reprod Dev 73: 1338-1344

Bousseau S, Brillard JP, Marquant-Le Guienne B, Guerin B, Camus A, Lechat M 1998: Comparison of bacteriological qualities of various egg yolk sources and the in vitro and in vivo fertilizing potential of bovine semen frozen in egg yolk or lecithin based diluents. Theriogenology 50: 699-706

Cao HL, Sun XZ, Li QW, Zhou SX, Nan XB, Hu JH, Wang LQ, He YM 2013: Testing Rhodiola sachalinensis saccharide as cryoprotectant for bovine spermatozoa. J Dairy Sci 96: 6965-6972

Crespilho AM, Sá Filho MF, Dell’Aqua JA Jr, Nichi M, Monteiro GA, Avanzi BR, Martins A, Papa FO 2012: Comparison of in vitro and in vivo fertilizing potential of bovine semen frozen in egg yolk or new lecithin based extenders. Livest Sci 149: 1-6

Hanuš O, Frelich J, Tomáška M, Vyletělová M, Genčurová V, Kučera J, Třináctý J 2010: The analysis of relationships between chemical composition, physical, technological and health indicators and freezing point in raw cow milk. Czech J Anim Sci 55: 11-29

Härtlová H, Rajmon R, Krontorádová I, Mamica J, Zita L, Klabanová P, Černocký A 2013: Semen quality, lipid peroxidation, and seminal plasma antioxidant status in horses with different intensities of physical exercise. Acta Vet Brno 82: 31-35

Hu JH, Li QW, Zan LS, Jiang ZL, An JH, Wang LQ, Jia YH 2010: The cryoprotective effect of low-density lipoproteins in extenders on bull spermatozoa following freezing-thawing. Anim Reprod Sci 117: 11-17

Karoui S, Díaz C, Serrano M, Cue R, Celorrio I, Carabaño MJ 2011: Time trends, environmental factors and genetic basis of semen traits collected in Holstein bulls under commercial conditions. Anim Reprod Sci 124: 28-38

Manjunath P, Nauc V, Bergeron A, Ménard M 2002: Major proteins of bovine seminal plasma bind to the lowdensity lipoprotein fraction of hen's egg yolk. Biol Reprod 67: 1250-1258

Maurya VP, Tuli RK 2003: Post-thaw thermal resistance test on motility and acrosomal integrity of filtered and non-filtered frozen semen of Murrah buffalo bulls. Asian Aust J Anim Sci 16: 1424-1428

Medeiros CMO, Forell F, Oliveira ATD, Rodrigues JL 2002: Current status of sperm cryopreservation: why isn't it better? Theriogenology 57: 327-344

Moussa M, Martinet V, Trimeche A, Tainturier D, Anton M 2002: Low density lipoproteins extracted from 
hen egg yolk by an easy method: cryoprotective effect on frozen-thawed bull semen. Theriogenology 57: $1695-1706$

Pace MM, Graham EF 1974: Components in egg-yolk which protect bovine spermatozoa during freezing. J Anim Sci 39: 1144-1149

Přinosilová P, Kopecká V, Hlavicová J, Kunetková M 2014: Modified hypoosmotic swelling test for the assessment of boar and bull sperm sensitivity to cryopreservation. Acta Vet Brno 83: 313-319

Siddique M, Ali R, Raza A 2006: Effect of buffers on freezing of buffalo bull semen. J Agri Soc Sci 2: 117-119

Stradaioli G, Noro T, Sylla L, Monaci M 2007: Decrease in glutathione (GSH) content in bovine sperm after cryopreservation: Comparison between two extenders. Theriogenology 67: 1249-1255

Špaleková E, Makarevich AV, Kubovičová E, Ostró A, Chrenek P 2014: Effect of caffeine on functions of coolingstored ram sperm in vitro. Acta Vet Brno 83: 19-25

Thara KM, Nair SP 2007: Sire effect on in vitro fertilizability of matured cattle oocytes. Indian J Biotechnol 6 : 421-422

Vera-Munoz O, Amirat-Briand L, Bencharif D, Anton M, Desherces S, Shmitt E, Thorin C, Tainturier D 2011: Effect of low-density lipoproteins, spermatozoa concentration and glycerol on functional and motility parameters of bull spermatozoa during storage at 4 degrees C. Asian J Androl 13: 281-286

Vishwanath R, Shannon P 2000: Storage of bovine semen in liquid and frozen state. Anim Reprod Sci 62: 23-53

Walsh SW, Williams EJ, Evans ACO 2011: A review of the causes of poor fertility in high milk producing dairy cows. Anim Reprod Sci 123: 127-138

Watson PF 2000: The causes of reduced fertility with cryopreserved semen. Anim Reprod Sci 60: 481-492 